\title{
Optimization of Large Multiple Coil Systems for Pulsed Magnets
}

\author{
J.A.A.J. Perenboom • P. Frings · J. Béard • \\ B. Bansal · F. Herlach · Tao Peng $\cdot$ S. Zherlitsyn
}

Received: 22 July 2009 / Accepted: 1 December 2009 / Published online: 12 January 2010

(C) The Author(s) 2010. This article is published with open access at Springerlink.com

\begin{abstract}
Very high pulsed magnetic fields can be generated more economically using a system of multiple coils, with a high-energy, limited-power pulse generator providing the background field for a smaller inner coil, energized in its turn, but for a much shorter pulse duration, with a very high-power, limited-energy generator. Because of the increased number of parameters in the design of multi-coils, systematic insight into their mutual dependence is helpful in order to converge to an optimized design.

In this paper we will discuss strategies to determine the optimum choice for the design of inner- and outer-coil and how to optimize their design in relation to the type of pulse generator used. In particular, we will consider energy-limited capacitor banks and power-limited supplies. The approach will use scaling arguments and modeling tools as the 'Pulsed Magnet Design Software' (PMDS) package, developed at the Katholieke Universiteit Leuven and Huazhong University of Science and Technology.
\end{abstract}

J.A.A.J. Perenboom $(\bowtie) \cdot$ B. Bansal

High Field Magnet Laboratory, Institute for Molecules and Materials, Radboud University, Toernooiveld 7, 6525 ED Nijmegen, The Netherlands

e-mail: J.Perenboom@science.ru.nl

P. Frings · J. Béard

Laboratoire National des Champs Magnétiques Intenses, CNRS, 143 Avenue de Rangueil, 31400 Toulouse, France

F. Herlach

Katholieke Universiteit Leuven, Celestijnenlaan 200 D, 3001 Heverlee, Belgium

T. Peng

Wuhan High Magnetic Field Center, Huazhong University of Science and Technology,

Wuhan 430074, China

S. Zherlitsyn

Hochfeld-Magnetlabor Dresden, Forschungszentrum Dresden-Rossendorf, 01314 Dresden, Germany 
Optimization of coil systems is demonstrated with the example of the successful $87 \mathrm{~T}$ pulsed dual-coil system in Dresden.

Keywords Pulsed magnets $\cdot$ Modeling

\section{Why Multi-coils?}

A large coil can give higher field (and/or longer pulse duration), but for a single coil this may require high energy at power levels that cannot be supplied by a feasible source. The energy- or power-supplies tend to be the most expensive part of the installation and a combination of high power and high energy is extremely expensive. Pulsed field coils can be energized either by a pulsed energy source or a pulsed power supply, and Table 1 lists the pulse generators available in Dresden, Nijmegen and Toulouse.

The performance of a coil is limited by the Lorentz force on the conductor and by ohmic heating. To generate high magnetic fields in a non-destructive way one builds coils with conductor materials that combine optimal strength and conductivity. The strength can be brought about by inherent strength of the conductor itself and by external and distributed reinforcement.

The power needed can be kept within acceptable limits by using a system of multiple coils. The 'ARMS' two-coil system [1,2] has delivered the proof of principle that it is possible to obtain very high non-destructive pulsed fields by combining a large-energy long-pulse (and thus large-volume) coil with a small coil made of highstrength material. In a multi-coil system, the increased design freedom allows to optimize the strength, pulse duration and heating of the coil, and to optimize the selection of materials and pulse generators. One can so also minimize damage in case of failure of one of the coils.

\section{Optimization}

Coil optimization is a rather complicated non-linear process, and it must also be clear what one would like to establish: the highest field, a certain bore-size, the pulse duration, choice of materials, etc. For multi-coils an important question is how best to choose the outer diameter of the innermost coil.

Table 1 Pulse generators for dual coils at the participating laboratories

\begin{tabular}{lccll}
\hline Laboratory & Voltage & Power & Stored energy & Short circuit \\
\hline HLD Dresden & $24.0 \mathrm{kV}$ & $4500 \mathrm{MW}$ & $15 \times 2.88 \mathrm{MJ}$ & $25 \mathrm{kA} /$ module \\
& $24.0 \mathrm{kV}$ & $1600 \mathrm{MW}$ & $4 \times 1.44 \mathrm{MJ}$ & $36 \mathrm{kA} / \mathrm{module}$ \\
& $24.0 \mathrm{kV}$ & $1100 \mathrm{MW}$ & $0.90 \mathrm{MJ}$ & $100 \mathrm{kA}$ \\
\hline LNCMI Toulouse & $24.0 \mathrm{kV}$ & $600 \mathrm{MW}$ & $10 \times 1.44 \mathrm{MJ}$ & $6.5 \mathrm{kA} / \mathrm{module}$ \\
& $24.0 \mathrm{kV}$ & $260 \mathrm{MW}$ & $1.14 \mathrm{MJ}$ & $40 \mathrm{kA}$ \\
\hline HFML Nijmegen & $1.0 \mathrm{kV}$ & $20 \mathrm{MW}$ & Power converter & $20 \mathrm{kA}$ \\
& $16.0 \mathrm{kV}$ & $360 \mathrm{MW}$ & $3 \times 0.67 \mathrm{MJ}$ & $20 \mathrm{kA} / \mathrm{module}$ \\
\hline
\end{tabular}



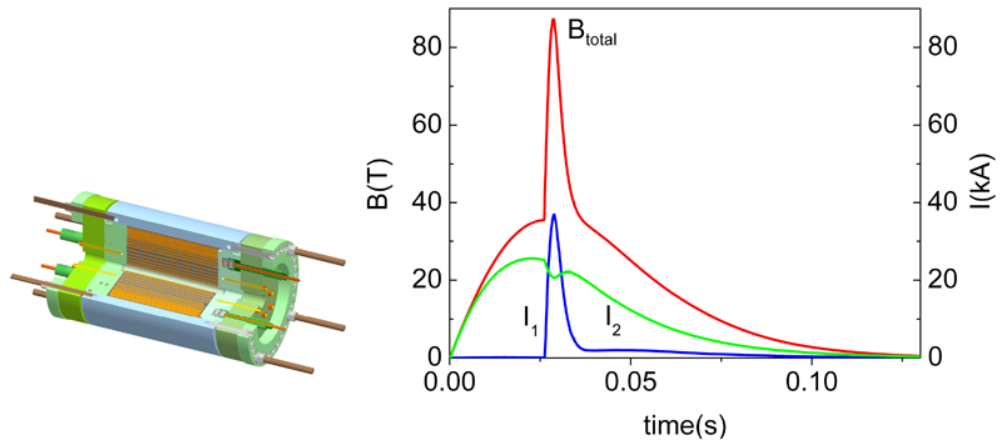

Fig. 1 (Color online) Left: Compact dual coil of HLD Dresden. Right: Magnetic field pulse to $87 \mathrm{~T}$ produced by the dual coil

Only severe limitation of the boundary conditions combined with simplification of mechanical and thermal problems permits optimization with analytical methods. Starting from successful and working designs, one can proceed to a parametrization of the coils characterized by the geometry (bore radius $a_{1}, \alpha=a_{2} / a_{1}$ the ratio of outer and inner radius, $\beta=h / 2 a_{1}$ ratio of half height and inner radius), filling factor $(f)$ and current density $(j)$. The number of turns and current density is inversely proportional to the conductor cross-section, and therefore $R=N^{2} R^{*}$. Since $R^{*}=R / N^{2}$ and $L^{*}=L / N^{2}$ are independent of the section and only depend on the geometry, the time constant $\tau=L / R=L^{*} / R^{*}$ and the magnetic energy $E=(1 / 2) L I^{2} \propto(1 / 2) j^{2} L^{*}$ are independent of the choice of the section as well. The conductor cross-section can thus be fixed in the end and adapted to the voltage and current of a given pulse generator.

Using scaling arguments one can then predict the behavior (peak field, magnetic energy, pulse duration, stress levels) of similar coils with different size or aspect ratio. In a multi-coil system the stresses will also depend on the field contribution of the outer coil(s), and one has to take into account the mutual inductance between the coils: this leads to a dip in the (longer) pulse of the outer coil (see Fig. 1) and somewhat enhanced current in the inner coil.

The software package PMDS, developed for the design of coils with optimized internal reinforcement by fibre composites, is a useful tool for the design of pulsed magnets, both monolithic and dual-coil [3], and the results of calculations are in good agreement with experiment and with ANSYS finite element calculations within the uncertainties of the detailed description of the coil and the material properties.

The design of a dual-coil system with PMDS proceeds as follows: First, some outer coils are designed that can be energized by the existing large pulse generator. A fairly small series of designs will provide an adequate survey of available combinations of outer field and bore. Then inner coils are designed with the strongest available materials that fit into the bore of the outer coils.

Typically the energy needed for the relatively small inner coil is not more than about a megajoule. Strong materials have higher resistivity; this calls for high voltage at high current. The relatively low energy of the generator for the inner coil gives 
some freedom of choice of a suitable supply, but the large generator for the outer coil(s) must be regarded as given and fixed.

For the power-limited generator of HFML in Nijmegen [4], one can start with an optimally power-efficient outer-coil design, $\kappa=\alpha / \beta=2 a_{2} / h \approx 1.66$, and accommodate the $2 \mathrm{MJ}$ energy of the capacitor bank for the inner coil. The low voltage of the $20 \mathrm{MW}$ power converter was a limiting factor (because the maximum conductor section that can be obtained and wound is limited) with outer coils becoming large $\left(a_{1}>110 \mathrm{~mm}\right)$ but low field $(25-30 \mathrm{~T})$, and the maximum attainable fields in $20 \mathrm{~mm}$ bore will therefore not exceed $80 \mathrm{~T}$.

The HLD in Dresden minimized the distance between the outermost winding of the inner coil and the inner diameter of the outer coil. They removed the axial tierods which are typically used for the axial support of monocoils, and transfered the axial support of the magnet to a steel cylinder tightening the flanges with bolts directly screwed into the cylinders. It makes the inner coil compact [5].

A $20 \mathrm{~mm}$ inner bore, dual-coil magnet of even more compact design, with the outer coil wound directly over the layer of reinforcement of the inner coil, has recently produced $87 \mathrm{~T}$ (see Fig. 1), using 0.8 MJ for the inner and 7.2 MJ for the outer coil. HLD aims to reach $100 \mathrm{~T}$ with the $50 \mathrm{MJ}$ capacitor bank [6].

\section{Conclusion}

The 'ARMS' two-coil system in Toulouse has demonstrated the generation of very high non-destructive pulsed fields by combining a long-pulse coil with a small coil made of high-strength material. Within the DeNUF project ('Design study for the next generation pulsed field magnet user facilities'), this principle has been optimized and adapted to the different energy sources of the partner facilities, i.e. a $14 \mathrm{MJ}$ capacitor bank in Toulouse, a $50 \mathrm{MJ}$ modular capacitor bank in Dresden and a $20 \mathrm{MW}$ power converter in Nijmegen. Several prototypes were built and tested in Toulouse and Dresden.

The new Toulouse dual coil, of rapid cooling type with the next pulse after only two hours, produced $81 \mathrm{~T}$, and the most recent Dresden prototype produced $87 \mathrm{~T}$, a new European record. Improved dual-coil systems are already under construction, promising further improved performance for the pulsed field user community.

Acknowledgements This work was supported by FP6 of the European Union through contract 011760, 'Design study for the next generation pulsed field magnet user facilities' (DeNUF).

Open Access This article is distributed under the terms of the Creative Commons Attribution Noncommercial License which permits any noncommercial use, distribution, and reproduction in any medium, provided the original author(s) and source are credited.

\section{References}

1. European Union 5th Framework program 'Advanced Research Magnet Systems' (ARMS), HPRI-CT1999-50007 
2. H. Jones, P. Frings, O. Portugall, M. von Ortenberg, A. Lagutin, F. Herlach, L. van Bockstal, IEEE Trans. Appl. Supercond. 16, 1684 (2006)

3. T. Peng, L. Li, J. Vanacken, F. Herlach, IEEE Trans. Appl. Supercond. 18, 1509 (2008)

4. J.A.A.J. Perenboom, K. Rosseel, P.A.J. Dolron, S.A.J. Wiegers, P.H. Frings, J.C. Maan, IEEE Trans. Appl. Supercond. 16, 1668 (2006)

5. S. Zherlitsyn, A.D. Bianchi, T. Hermannsdörfer, F. Pobell, Yu. Skourski, A. Sytcheva, S. Zvyagin, J. Wosnitza, IEEE Trans. Appl. Supercond. 16, 1660 (2006)

6. S. Zherlitsyn, T. Hermannsdörfer, Y. Skourski, A. Sytcheva, J. Wosnitza, J. Low Temp. Phys. 146, 719 (2007) 